\title{
El principio del cambio o la continuación histórica de los errores
}

\author{
The principle of change or the historic continuation of errors
}

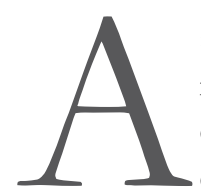

sistimos por estos días, nuevamente, a la apertura de los espacios de diálogo y encuentro entre los representantes de la institucionalidad política, militar y económica y los líderes de la guerrilla más vieja del mundo, en lo que podríamos llamar el enésimo intento de resolución concertado del conflicto social y armado colombiano. En la profundidad de la conciencia colectiva y de los anhelos más fundamentales, las comunidades y los pueblos se ilusionan con un justo acuerdo que permita cesar con la lluvia de sangre que los espacios de la civilidad ha tenido que ofrendar al dios de la guerra durante varias décadas, a nombre de la avaricia, el egocentrismo e ilimitación del poder. Asimismo, las fuerzas más retrógradas y conservadoras de nuestra sociedad dudan del proceso y se entusiasman con su inminente fracaso; fuerzas que han hecho del belicismo y de la militarización de la sociedad una forma de vida y una manera de reproducción de estructuras históricas devenidas necesarias e inmanentes al ser colectivo nacional.
Sin embargo, nuestras dudas sobre el proceso recién abierto son de otra índole que las del statu quo o, específicamente, que las del estamento militar conservador. Éstas se basan en varios aspectos que es conveniente clarificar, para evitar caer nuevamente en errores del pasado que han hecho de los diálogos de paz un motivo para el fortalecimiento del paramilitarismo y de las fuerzas subversivas, así como una instancia de justificación de la barbarie como horizonte de resolución del conflicto.

Lo primero que hay que señalar es que las posibilidades profundas y verdaderamente significativas de la transformación social en Colombia están más allá de la retórica institucional y guerrillera de los buenos propósitos de un futuro sin conflictos, de la reconciliación definitiva o de la superación de las contradicciones. El amplio espectro de la conflictividad social es tan constitutivo a las comunidades como las instituciones que representan a los ciudadanos de un territorio

1 Diego Fernando Silva Prada es Doctor en Ciencias Sociales de FLACSO - Argentina. Investigador del CEIHS.

2 Oscar Useche Aldana es el Director de la Revista Polisemia. 
o como las relaciones de producción en las sociedades capitalistas. El país debe entender que la anhelada paz es un largo e inacabable proceso de transformación sociocultural de las estructuras y de las relaciones de dominación generadoras de lo que hemos llegado a ser. Esas relaciones de dominación y esos elementos que se mantienen en el tiempo como condicionantes de la vida de las personas seguirán estando presentes en el futuro deseado. El asunto que debe evaluarse en los diálogos es, entonces, el de cómo construir las condiciones de posibilidad para depotenciar la máquina de guerra, de muerte, en la que se ha convertido el Estado colombiano, generador de actores bélicos de todas las especies. Hay por tanto que diferenciar la conflictividad social esencial y las expresiones más destructivas y negativas que adquiere esa conflictividad, para incidir puntualmente en su desactivación o desarticulación.

El segundo elemento es el de la cuestión de las voces que se sientan a la mesa. Para la mayoría está más que claro que si el conflicto armado compromete a un porcentaje altamente significativo de la población civil en lo que ha sido su bienestar individual y colectivo, ésta debe estar representada y debe tener un asiento en la construcción de los acuerdos de la sociedad que queremos. Realmente no se entiende porque las víctimas, de uno y otro lado, hayan de quedar excluidas de la definición del futuro y que sus voces no ayuden a clarificar ese pasado atroz que requiere ser aceptado en sus responsabilidades. La lógica de consolidación de los acuerdos tiene que estar sustentada en la importancia o igualdad en el peso político de los diferentes actores del conflicto, tanto militares como civiles. Esta primera incongruencia del proceso demuestra la contradicción que ha estado enquistada en la historia de la guerra en Colombia: los supuestos representantes de los diversos intereses no han sido tal. Las diferentes organizaciones de la sociedad civil tienen, cada una, una voz y una posición política propia que no debe por que ser cooptada por ningún actor en armas, bajo el pretexto de la representación de los que no tienen voz.

La tercera cuestión es la de la transformación de las proporciones que la economía de guerra posee en la vida nacional. Hablamos, por un lado, de la necesidad de la reducción del porcentaje del Producto Interno Bruto que se lleva el presupuesto del Ministerio de Defensa y el gasto militar de todas las fuerzas armadas (aproximadamente un $5.3 \%$ o unos 11.7 billones de pesos para el año 2008), el cual es muy superior al de cualquier otro país de América Latina. Pero, por otro lado, las consecuencias derivadas de la desmilitarización que conllevaría un cese al fuego y una dejación de las armas de las miles de personas que tienen como sustento material la guerra. La experiencia de la Ley de Justicia y Paz con los paramilitares nos ha enseñado que si no existen verdaderas oportunidades de reinserción a la civilidad con proyectos de vida factibles y dignos, la violencia política termina transmutando en diversidad de formas de delincuencia común, en la reorganización de estructuras mafiosas o en expresiones de violencia urbana como las surgidas en Centro América, luego de los acuerdos de paz de los años 90.

Además de lo anterior, el país tiene que estar preparado para dar el paso definitivo de aceptar las diferencias ideológicas como constitutivas a la cotidianidad política de la nación, dentro de un modelo de sociedad que intenta cerrar las inmensas brechas de injusticia, inequidad y discriminación en las que sobrevive. Es decir, que los diálogos, para que no sean nuevamente la repetición de los errores históricos cometidos en el pasado reciente y lleguen a ser el comienzo de un verdadero cambio, necesitan enfrentar estratégicamente tanto a la violencia directa promovida por los actores armados y las élites económicas, como a la violencia indirecta de las estructuras históricas de empobrecimiento y marginalidad. La anhelada legitimidad del Estado se construye en el equilibrio de estos dos factores que pueden llegar a solidificar eso que creemos es una paz so- 
cial amplia, profunda y duradera. Por lo menos, esta ha sido la apuesta política y ética que la Corporación Universitaria Minuto de Dios, la Facultad de Ciencias Humanas y Sociales y del Centro de Estudios e Investigaciones Humanas y Sociales ha venido desarrollando desde los espacios académicos, pedagógicos e investigativos.

Para la presente edición, cuatro artículos resultado de investigación componen la primera sección de Polisemia; tres más, la sección de reflexión; una entrevista y una reseña cierran el número 13 de nuestra revista. Gilma Liliana Ballesteros Peluffo, con Arte y desobediencia civil, nos señala la función política de denuncia y de protesta implícita en las expresiones artísticas como las de Goya, Picasso, Rivera y Kahlo. Los temas por los que transitan sus obras de arte son recurrentes: la guerra, la pobreza y la desigualdad. El sinsentido de todas éstas es plasmado de manera magistral por conciencias críticas de las sociedades de sus respectivos tiempos. El arte se convierte, entonces, en una invitación sublime a desobedecer civilmente, rompiendo con la naturalidad de la guerra, el orden y el statu quo.

Por su parte, Cristina Isabel Carmona Portocarrero, en Intervención al duelo por ruptura de pareja desde la terapia cognitivo conductual a partir del análisis de cuatro casos, identifica las principales respuestas de duelo en los casos de ruptura de pareja heterosexual. Aplicando el método psicoterapéutico cognitivo conductual se llega a la conclusión de que en la experiencia de la ruptura de pareja se necesita reestructurar los pensamientos que generan el sufrimiento, o lo que es lo mismo, el malestar significativo que impide la elaboración de la pérdida. El objetivo es que el paciente aprenda a aceptar la ruptura, construir esperanza con respecto a la continuidad de la vida e iniciar nuevos vínculos que sobrepasen el odio, la desconfianza y la victimización.

Esteban Arias Ardila presenta Un proyecto de Dios que defiende los intereses del imperio. Lectura crítica del libro de Nehemías desde los artifices opositores, realizando una interpretación de la es- tructura literaria del libro de Nehemías, enfocándola desde la óptica de los opositores frente a la propuesta central del libro que favorece la incidencia del Imperio Persa, a través de Nehemías y Esdras, en la Palestina de la época del retorno de los judíos a su tierra después del destierro babilónico. El grupo de los opositores a la propuesta de reconstrucción de Jerusalén y de la nueva provincia persa se caracterizó por su influencia en la región y por el impulso a una reforma de nacionalismo autónomo que no contaba con el auspicio político de los persas. Se finaliza el artículo con la relación entre la propuesta de Nehemías y el conflicto colombiano como posibilidad de desarme de la población, de realización de proyectos económicos para las comunidades marginadas, del apoyo al retorno de la población desplazada y de la conversión de las iglesias en centros de ayuda humanitaria, promotores de la justicia social.

En El debate entre la educación republicana y la neoliberal en Chile, Jorge Vergara Estévez reconstruye la comparación entre la concepción neoliberal de la educación y la propuesta republicana retomada por la actual movilización estudiantil chilena. Desde la primera y bajo el influjo del pensamiento de Friedman, la educación pública es concebida como una anomalía y debe retornar al ámbito de lo privado, desnacionalizándola, desestatalizándola, pero asegurando una reproducción de los valores individualistas y de mercado. La educación sería, en últimas, un servicio y una inversión que generaría valorización en el capital humano, desde un sistema privatizado y competitivo. Frente a esta forma, a partir del republicanismo de Montesquieu y Rousseau, la educación cumple una función trascendental en la construcción de la sociedad, tomando en cuenta las ideas de la virtud política y la formación del ciudadano como una necesaria profundización de la democracia. Para el caso chileno, la demanda de una "educación pública, gratuita y de calidad" se basa en un republicanismo posible y necesario para una sociedad con menos desigualdades. Finalmente, todo país necesita definir 
sus políticas públicas de educación a parir del diálogo y la constitución de consensos con los actores involucrados.

Abriendo la sección de los artículos de reflexión, Juan Carlos Marulanda Hernández, con El emotivismo y su influencia en las teorías contemporáneas del desarrollo moral, rescata la dimensión emotiva para la fundamentación de los juicios morales y las teorías del desarrollo moral. Las emociones no deben ser vistas como un impedimento que tengan que estar dominadas por la razón, sino que pueden ser interpretadas como las constructoras de los conceptos de bueno y malo y, por lo tanto, no son un momento negativo en la moralidad. A partir del análisis del pensamiento de Thomas Hobbes y David Hume, se puede entender la subordinación que existe de la razón a los sentidos y cómo la razón es un producto derivado de los sentidos. Es por lo tanto necesario reconocer la influencia de estas filosofías más allá de las fronteras disciplinares y relacionarlas con las teorías del desarrollo moral en Psicología.

Cesar Augusto Pinzón Torres con Normal y anormal: discursos y prácticas de la segregación reflexiona sobre las consecuencias derivadas de los discursos y prácticas referidas a los conceptos de normalidad y anormalidad. Retomando el pensamiento foucaultiano sobre la edificación de la legitimidad del discurso sobre la anormalidad como conducta desviada, se entiende la dimensión política intrínseca a las prácticas psiquiátricas de control del comportamiento y de definición de la normalidad. La medicalización del cuerpo entra en escena como una estrategia más para la creación del orden social burgués. Asimismo, la apropiación de los discursos por parte de las instituciones cerrará el cerco social de la delimitación segregacionista entre la normalidad y la anormalidad, entre lo permitido y lo prohibido.

Para finalizar esta sección, Víctor Eligio Espinosa Galán, en el texto titulado Formación, subjetividad y escuela: aproximación fenomenológica al tiempo escolar lleva a cabo un interesante análisis en perspectiva fenomenológica del tiem- po escolar, a partir de los aportes de Husserl, retomando la obra Lecciones de fenomenología de la conciencia interna del tiempo. La formación no se da solamente como experiencia objetiva del tiempo institucional, sino, como dice el autor: "La formación es un acontecimiento de sentido individual", porque en últimas es el sujeto el que termina formándose, otorgándole un sentido a su presente y en comunicación constante con el futuro y con el pasado. No obstante, los retos del presente en cuanto a la formación de los jóvenes de hoy radican en la reproducción, por parte de los medios tecnológicos, de un tiempo virtual impersonal y acá es donde habrá que pensar nuevamente la cuestión de la formación.

Como suplemento, se reproduce la entrevista realizada en noviembre de 2011 a la activista del movimiento estudiantil chileno Camila Vallejo. En ésta se abordan los temas de la vigencia de la izquierda, el surgimiento y las causas de actual movimiento estudiantil, los apoyos y las redes construidas, los medios de comunicación en el contexto de la lucha educativa, así como el futuro del movimiento y el proyecto de país que está por edificarse. Finalmente, hay que resaltar el ánimo de la acción política emprendida por la movilización estudiantil chilena al ir más allá de lo puramente sectorial y cuestionar el modelo de una sociedad privatizada que debe ser revaluada en sus aspectos democráticos y sociales.

Para cerrar este número de nuestra revista, Miguel Ángel Ariza Díaz, Jhon Diego Domínguez Acevedo y Kevin Daniel Rozo Rondón en la sección de reseñas presentan Ecos de la Marsellesa. Dos siglos recuerdan la Revolución Francesa, haciendo alusión al texto de Eric Hobsbawm, en cuanto a la vigencia del espíritu revolucionario aun vigente, en oposición al conservadurismo francés de la escuela revisionista.

Esperamos que los artículos aquí presentes puedan generar en el lector el fructífero diálogo y el necesario debate de las ideas, consubstancial a la perspectiva crítica y a la comunidad académica en consolidación. 